\title{
Hematologic modifications in natalizumab-treated multiple sclerosis patients
}

\author{
An 18-month longitudinal study
}

\section{OPEN}

Claire Bridel, $\mathrm{MD}, \mathrm{PhD}^{*}$

Yan Beauverd, MD*

Kaveh Samii, MD

Patrice H. Lalive, MD

Correspondence to

Prof. Lalive:

patrice.lalive@hcuge.ch

\section{ABSTRACT}

Objective: To monitor the hematologic modifications in the peripheral blood of patients with relapsing-remitting multiple sclerosis treated with natalizumab.

Methods: The cohort included 44 patients with relapsing-remitting multiple sclerosis treated monthly with natalizumab for 18 months. Peripheral blood was collected before treatment initiation and on a monthly basis during the treatment course. Complete blood cell count was performed using automated hematology systems. Blood smears were prepared and analyzed when abnormal values were detected.

Results: Mean total white blood cell, lymphocyte, and eosinophil counts were significantly higher 1 month after treatment initiation and remained stable during the 18 months of follow-up. Monocyte counts increased progressively during the 18-month treatment with natalizumab. Erythroblasts and neutrophil precursors were absent before treatment initiation but were present in $16 \%$ and $6.8 \%$ of patients, respectively, 1 month after the first natalizumab infusion. The proportion of patients with erythroblasts and neutrophil precursors remained stable throughout the 18-month follow-up period. On an individual patient basis, a fluctuating level of erythroblasts and neutrophil precursors was observed. No difference in mean erythrocyte, hemoglobin, hematocrit, thrombocyte, and neutrophil levels was observed before and after 18 months of natalizumab treatment. No cases of myelodysplastic syndrome or acute leukemia were observed.

Conclusion: Chronic treatment with natalizumab is associated with significant modifications in complete blood cell count, including emergence of hematopoietic precursors that are not present in peripheral blood under normal conditions. None of these modifications were associated with malignancy. Neurol Neuroimmunol Neuroinflamm 2015;2:e123; doi: 10.1212/ NXI.0000000000000123

\section{GLOSSARY}

MS = multiple sclerosis; NTZ = natalizumab; PB = peripheral blood; RRMS = relapsing-remitting MS

Natalizumab (NTZ) is a humanized monoclonal IgG4 antibody directed against the $\alpha 4$ subunit of human integrins $\alpha 4 \beta 1$ (or VLA-4) and $\alpha 4 \beta 7$ (or LPAM), both expressed on leukocytes. Used as a treatment for multiple sclerosis (MS), NTZ inhibits the adhesion of leukocytes to vascular cell adhesion molecule 1 on activated endothelial cells. The inhibition of T lymphocyte transmigration into the brain parenchyma is thought to underlie most of the therapeutic effects of NTZ in MS. ${ }^{1}$

NTZ treatment is associated with modifications in various peripheral blood (PB) parameters. $^{2-5}$ In this 18 -month longitudinal study, we monitored all the PB parameters measured in routine blood analysis. Forty-four patients with relapsing-remitting MS (RRMS) for whom the decision to treat with NTZ had been made by their neurologist were included in the study.

\footnotetext{
*These authors contributed equally to this manuscript.

From the Department of Clinical Neurosciences (C.B., P.H.L.), Division of Neurology, Unit of Neuroimmunology and Multiple Sclerosis;

Department of Hematology (Y.B., K.S.); and Department of Genetics and Laboratory Medicine (P.H.L.), Laboratory Medicine Service, University Hospital of Geneva, Switzerland.

Funding information and disclosures are provided at the end of the article. Go to Neurology.org/nn for full disclosure forms. The Article Processing Charge was paid by the authors.

This is an open access article distributed under the terms of the Creative Commons Attribution-NonCommercial-NoDerivatives License 4.0 (CC BY-NC-ND), which permits downloading and sharing the work provided it is properly cited. The work cannot be changed in any way or used commercially.
} 


\begin{tabular}{|c|c|}
\hline Patient demographics & \\
\hline No. of patients & 44 \\
\hline Sex, \% female & 81.2 \\
\hline Mean age at treatment onset, y (range) & 39 (26-69) \\
\hline $\begin{array}{l}\text { Mean disease duration at treatment onset, } \\
\text { y (range) }\end{array}$ & $7(0-23)$ \\
\hline
\end{tabular}

PB analysis was performed before NTZ initiation and on a monthly basis after treatment initiation. The follow-up period was 18 months for all patients. In this report, we summarize the modifications of $\mathrm{PB}$ parameters observed in these patients and comment on the kinetics of these modifications as well as their significance in terms of safety.

METHODS Forty-four patients with RRMS were treated with a monthly infusion of $300 \mathrm{mg}$ NTZ. Ethylenediaminetetraacetic acid-anticoagulated PB was collected and analyzed before treatment initiation (NTZ-naive patients) and on a monthly basis during an 18-month period of follow-up. Thirteen parameters were analyzed in each blood sample: hemoglobin and hematocrit levels and erythrocyte, white blood cell, neutrophil, neutrophil precursor (defined as myelocytes and metamyelocytes), eosinophil, basophile, monocyte, thrombocyte, and erythroblast counts.

Complete blood count, which measures several components and features of blood, including red blood cells, hemoglobin, hematocrit, white blood cells, and platelets, was analyzed with Sysmex XE-2100/XE-5000 (Sysmex, Kobe, Japan). This automated hematology system is validated to detect nucleated red blood cells. ${ }^{6,7}$ All abnormal values detected by the automated system were signaled, and blood smears were prepared and dyed with May-Grünwald-Giemsa stain and examined by light microscopy by an experienced laboratory assistant supervised by an experienced hematologist. Statistical analysis was performed with STATA release 12 (StataCorp, College Station, TX). Paired $t$ tests were used to compare means of different parameters before and after 18 months of NTZ treatment. The distribution of the differences was normal for each parameter. $p$ Values below 0.05 were considered significant.

Figure 1 Evolution of blood cell counts during 18-month treatment and follow-up

A
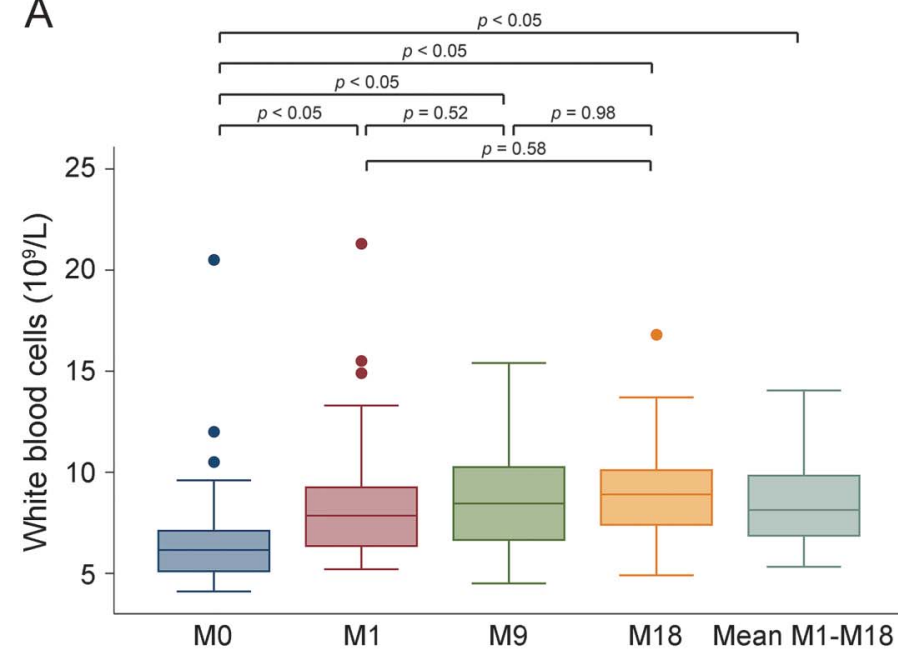

C
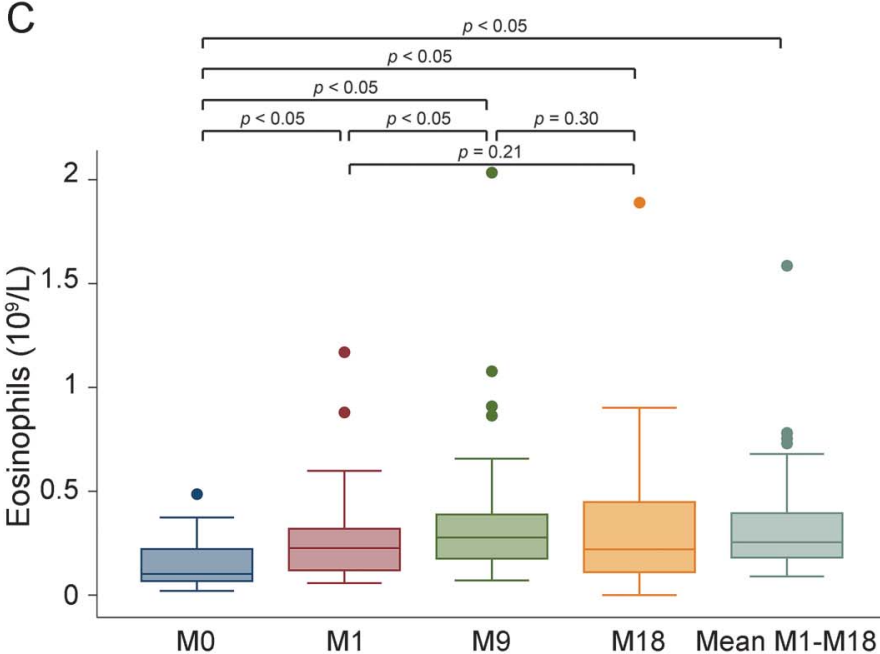

B
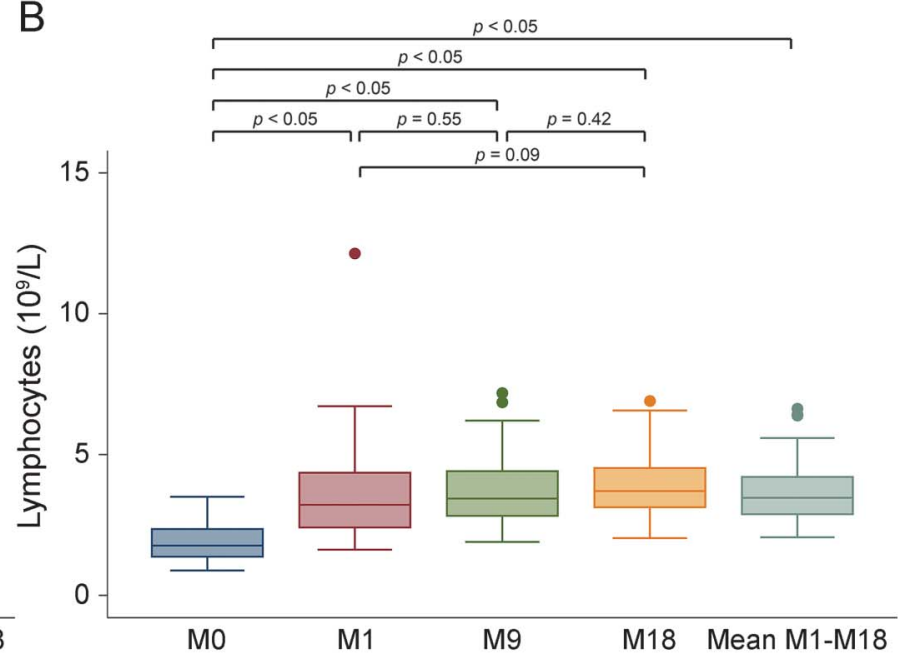

D

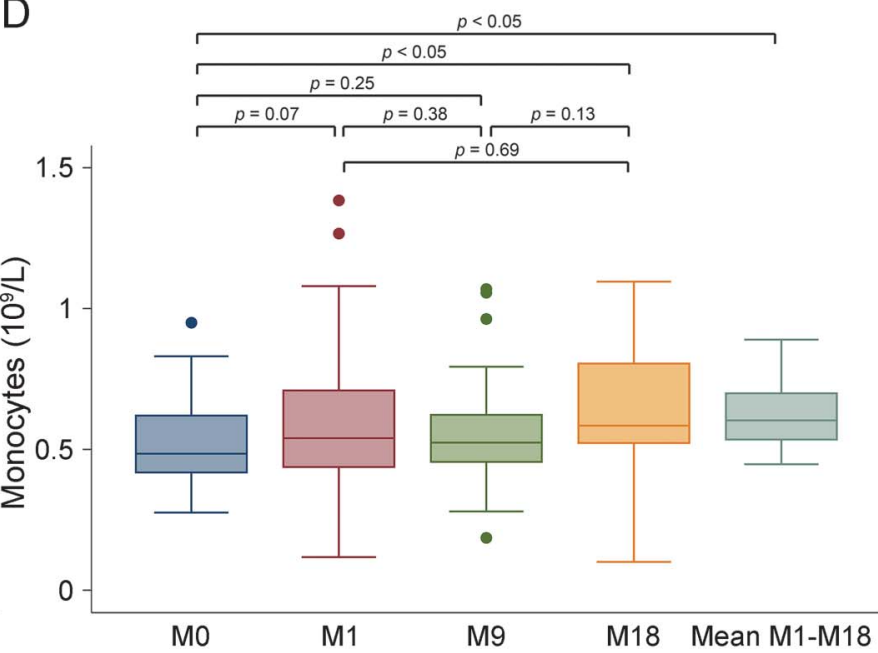

(A) Mean white blood cell count, (B) mean lymphocyte count, (C) mean eosinophil count, and (D) mean monocyte count before treatment (MO) and after 1 month (M1), 9 months (M9), and 18 months (M18) of treatment, and from months 1-18 (mean M1-M18). 
Standard protocol approvals, registrations, and patient consents. This study was exempt from requiring ethical approval per the Geneva Ethics Committee (reference number 14-151).

RESULTS Patient demographics and characteristics are shown in the table. There was no difference in mean erythrocyte, hemoglobin, hematocrit, thrombocyte, and neutrophil levels before and after 18 months of NTZ treatment (data not shown). Mean total white blood cell, lymphocyte, and eosinophil counts were significantly higher 1 month after the first NTZ infusion compared with pretreatment levels but remained stable during the next 17 months of follow-up (figure 1, A-C). Monocyte counts increased progressively over the 18-month followup, reaching significance after 18 months of treatment (figure 1D). No erythroblasts were detected in $\mathrm{PB}$ of patients with MS prior to NTZ treatment (figure 2A, first column). One month after the first infusion, 16\% (7/44) of patients had erythroblasts in PB. The proportion of patients with erythroblasts did not vary significantly throughout the 18-month follow-up period (figure 2A, columns 2-18). No neutrophil precursors (myelocytes and metamyelocytes) were detected in $\mathrm{PB}$ of patients with MS prior to NTZ treatment (figure $2 \mathrm{~B}$, first column). One month after the first infusion, $6.8 \%$ (3/44) of patients had neutrophil precursors in $\mathrm{PB}$ (figure 2B, second column). The proportion of patients with neutrophil precursors in $\mathrm{PB}$ did not vary significantly throughout the 18 -month follow-up period (figure 2B, columns 2-18). On an individual basis, some patients never showed hematopoietic precursors in PB. Those who did had fluctuating levels of erythroblasts and/or neutrophil precursors within the range of $0 \%-2 \%$ and $0 \%-3 \%$ of total peripheral blood cells, respectively. There was no trend toward an increase in these parameters during the 18-month follow-up. During NTZ treatment, plasmocytes were detected in 5 patients (11.4\%) and blasts in 1 patient (2.3\%). During the 18-month follow-up, no patient developed persistent cytopenia or other PB anomalies consistent with a myelodysplastic syndrome or acute leukemia.

DISCUSSION Elevated circulating lymphocyte, monocyte, and eosinophil counts have been reported in patients with MS treated with NTZ. ${ }^{2-5}$ This is thought to result from the transmigration inhibition of these cells into the CNS, which leads to their accumulation in $\mathrm{PB} .{ }^{2-5}$ In this study, we confirm these findings and show that the increase of total white blood cell, lymphocyte, and eosinophil counts in the PB of patients with MS treated with NTZ arises after the first NTZ infusion. Subsequently, the levels of these parameters remain stable during the entire follow-up period. Monocytes show a different, progressive pattern of increase during the 18-month treatment. NTZ treatment has been associated with the presence of hematopoietic stem/progenitor cells in $\mathrm{PB},{ }^{8}$ and erythroblastemia has been reported in chronically NTZ-treated patients with MS. ${ }^{2,9,10}$ Here, we show that hematopoietic precursors that are not present in $\mathrm{PB}$ under physiologic conditions are detectable as early as after the first NTZ infusion. These precursors include erythroblasts, neutrophil precursors, and blasts in 1 patient. The proportion of

Figure 2 Proportion of patients with erythroid and myeloid precursors before and during 18 months of treatment

A

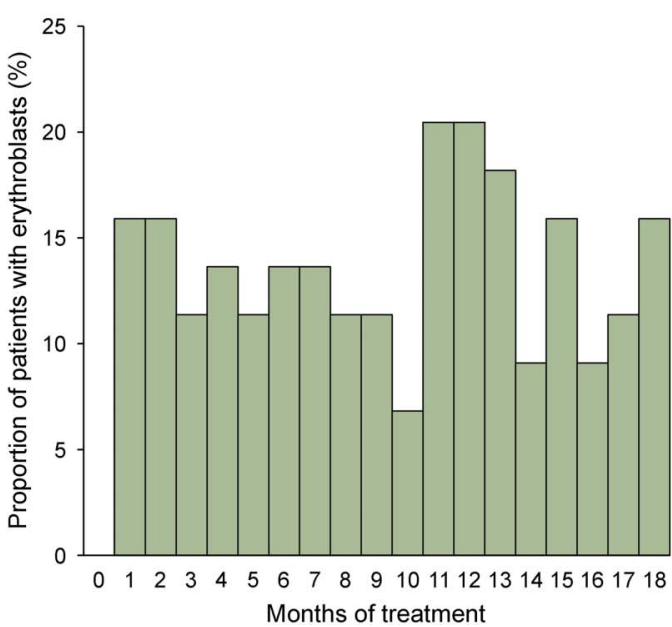

$\mathrm{B}$

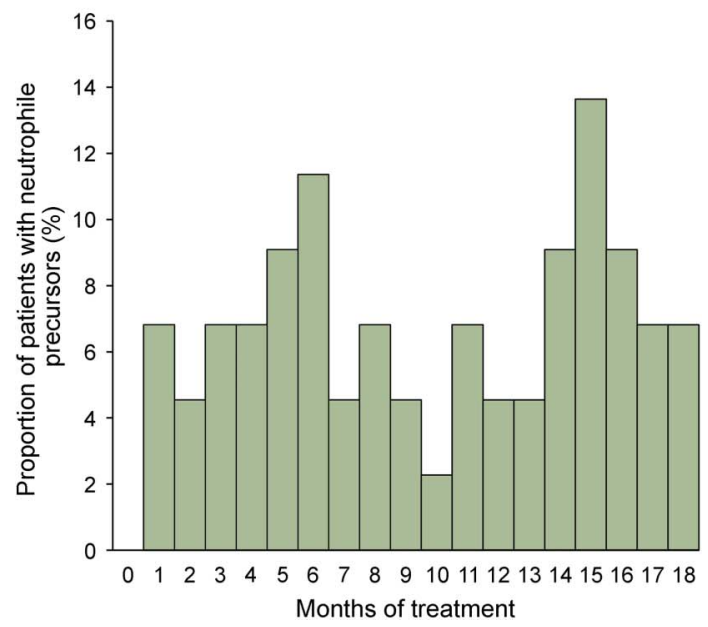

(A) Proportion of patients with 1 or more erythroblast(s) in peripheral blood (PB) during 18 months of follow-up. (B) Proportion of patients with 1 or more neutrophil precursor(s) in PB during 18 months of follow-up. 
patients with erythroblasts or neutrophil precursors remains stable over an 18-month period of follow-up, and on an individual basis, there is no trend toward an increase of these precursors in PB. $\alpha 4 \beta 1$ (VLA- 4 ) is expressed on the surface of erythroblasts, myeloblasts, and neutrophil precursors. Its interaction with fibronectin is essential in order to prevent these cells from exiting the bone marrow. ${ }^{11}$ Antibodies directed against $\alpha 4 \beta 1$, such as NTZ, have been shown to reduce interaction of these cells with fibronectin, ${ }^{11}$ which may explain their detection in the $\mathrm{PB}$ of treated patients. Finally, there was no indication of an evolution toward malignancy in any patient over the 18 -month period, although a longer period of follow-up is required to rule out such an eventuality. Recognition of these typical $\mathrm{PB}$ changes in patients with MS treated with NTZ prevents unnecessary diagnostic procedures such as bone marrow biopsy.

\section{AUTHOR CONTRIBUTIONS}

Claire Bridel: drafting/revising the manuscript, study concept or design, analysis or interpretation of data, statistical analysis. Yan Beauverd: drafting/revising the manuscript, study concept or design, analysis or interpretation of data, acquisition of data, statistical analysis. Kaveh Samii: drafting/revising the manuscript, analysis or interpretation of data. Patrice H. Lalive: drafting/revising the manuscript, study concept or design, analysis or interpretation of data.

\section{STUDY FUNDING}

No targeted funding reported.

\section{DISCLOSURE}

The authors report no disclosures. Go to Neurology.org/nn for full disclosure forms.

Received December 22, 2014. Accepted in final form March 30, 2015.

\section{REFERENCES}

1. Rice GP, Hartung HP, Calabresi PA. Anti-alpha4 integrin therapy for multiple sclerosis: mechanisms and rationale. Neurology 2005;64:1336-1342.

2. Polman $\mathrm{CH}, \mathrm{O}^{\prime}$ Connor PW, Havrdova E, et al. A randomized, placebo-controlled trial of natalizumab for relapsing multiple sclerosis. N Engl J Med 2006;354:899-910.

3. Gordon FH, Lai CW, Hamilton MI, et al. A randomized placebo-controlled trial of a humanized monoclonal antibody to alpha4 integrin in active Crohn's disease. Gastroenterology 2001;121:268-274.

4. Abbas M, Lalive PH, Chofflon M, Simon HU, Chizzolini C, Ribi C. Hypereosinophilia in patients with multiple sclerosis treated with natalizumab. Neurology 2011;77:1561-1564.

5. Sandborn WJ, Colombel JF, Enns R, et al. Natalizumab induction and maintenance therapy for Crohn's disease. N Engl J Med 2005;353:1912-1925.

6. Pipitone S, Pavesi F, Testa B, et al. Evaluation of automated nucleated red blood cells counting on Sysmex XE5000 and Siemens ADVIA 2120. Clin Chem Lab Med 2012;50:1857-1859.

7. Gulati G, Behling E, Kocher W, Schwarting R. An evaluation of the performance of Sysmex XE-2100 in enumerating nucleated red cells in peripheral blood. Arch Pathol Lab Med 2007;131:1077-1083.

8. Neumann F, Zohren F, Haas R. The role of natalizumab in hematopoietic stem cell mobilization. Expert Opin Biol Ther 2009;9:1099-1106.

9. Ransohoff RM. Natalizumab for multiple sclerosis. N Engl J Med 2007;356:2622-2629.

10. Robier C, Amouzadeh-Ghadikolai O, Bregant C, et al. The anti-VLA-4 antibody natalizumab induces erythroblastaemia in the majority of the treated patients with multiple sclerosis. Mult Scler 2014;20:1269-1272.

11. Kerst JM, Sanders JB, Slaper-Cortenbach IC, et al. Alpha 4 beta 1 and alpha 5 beta 1 are differentially expressed during myelopoiesis and mediate the adherence of human CD34+ cells to fibronectin in an activation-dependent way. Blood 1993;81:344-351. 


\title{
Neurology \\ Neuroimmunology \& Neuroinflammation
}

\author{
Hematologic modifications in natalizumab-treated multiple sclerosis patients: An \\ 18-month longitudinal study \\ Claire Bridel, Yan Beauverd, Kaveh Samii, et al. \\ Neurol Neuroimmunol Neuroinflamm 2015;2; \\ DOI 10.1212/NXI.0000000000000123
}

This information is current as of June 18, 2015

Updated Information \&

Services

References

Subspecialty Collections

Permissions \& Licensing

Reprints including high resolution figures, can be found at:

http://nn.neurology.org/content/2/4/e123.full.html

This article cites 11 articles, 1 of which you can access for free at: http://nn.neurology.org/content/2/4/e123.full.html\#\#ref-list-1

This article, along with others on similar topics, appears in the following collection(s):

Multiple sclerosis

http://nn.neurology.org//cgi/collection/multiple_sclerosis

Information about reproducing this article in parts (figures,tables) or in its entirety can be found online at:

http://nn.neurology.org/misc/about.xhtml\#permissions

Information about ordering reprints can be found online: http://nn.neurology.org/misc/addir.xhtml\#reprintsus

Neurol Neuroimmunol Neuroinflamm is an official journal of the American Academy of Neurology.

Published since April 2014, it is an open-access, online-only, continuous publication journal. Copyright $\odot$ 2015 American Academy of Neurology. All rights reserved. Online ISSN: 2332-7812.

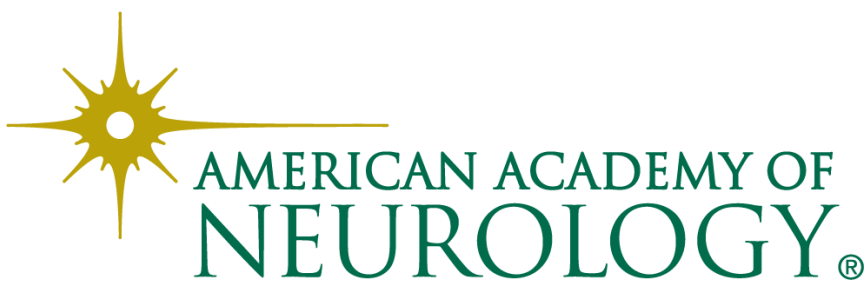

